\title{
Two families with Leber's hereditary optic neuropathy carrying G11778A and T14502C mutations with haplogroup H2a2a1 in mitochondrial DNA
}

\author{
CHEN QIAO ${ }^{1}$, TANWEI WEI $^{2}$, BO HU $^{3}$, CHUNYAN PENG $^{4}$, XUEPING QIU $^{4}$, LI WEI $^{1}$ and MING YAN ${ }^{1}$ \\ ${ }^{1}$ Department of Ophthalmology, Zhongnan Hospital of Wuhan University, Wuhan, Hubei 430071; \\ ${ }^{2}$ Department of Ophthalmology, Wuhan Puren Hospital, Wuhan, Hubei 430081; ${ }^{3}$ Department of Laboratory Medicine, \\ The Third Affiliated Hospital of Sun Yat-Sen University, Guangzhou, Guangdong 510630; ${ }^{4}$ Division of Hereditary Diseases, \\ Center for Gene Diagnosis, Zhongnan Hospital of Wuhan University, Wuhan, Hubei 430071, P.R. China
}

Received June 22, 2014; Accepted March 18, 2015

DOI: $10.3892 / \mathrm{mmr} .2015 .3714$

\begin{abstract}
The mitochondrial haplogroup has been reported to affect the clinical expression of Leber's hereditary optic neuropathy (LHON). The present study aimed to investigate the interaction between mutations and the haplogroup of mitochondrial DNA (mtDNA) in families. Two unrelated families with LHON were enrolled in the study, and clinical, genetic and molecular characterizations were determined in the affected and unaffected family members. Polymerase chain reaction direct sequencing was performed using 24 pairs of overlapping primers for whole mtDNA to screen for mutations and haplogroup. Bioinformatics analysis was performed to evaluate the pathogenic effect of these mtDNA mutations and the haplogroup. The G11778A mutation was identified in the two families. In addition, the members of family 2 exhibited the T14502C mutation and those in family 1 exhibited the T3394C and T14502C mutations, which were regarded as secondary mutations. The penetrance of visual loss in families 1 and 2 were 30.8 and $33.3 \%$, respectively. In addition, the two families were found to be in the H2a2a1 haplogroup. In this limited sample size, it was demonstrated that the $\mathrm{H} 2 \mathrm{a} 2 \mathrm{a} 1$ haplogroup had a possible protective effect against LHON. Additional modifying factors, including environmental factors, lifestyle, estrogen levels and nuclear genes may also be important in LHON.
\end{abstract}

\section{Introduction}

Leber's hereditary optic neuropathy (LHON; Online Mendelian Inheritance in Man \#535000) is characterized by the selective

Correspondence to: Professor Ming Yan, Department of Ophthalmology, Zhongnan Hospital of Wuhan University, 169 Donghu Road, Wuhan, Hubei 430071, P.R. China

E-mail: yanmingming1972@126.com

Key words: Leber's hereditary optic neuropathy, mitochondrial DNA mutation, G11778A, haplogroup degeneration of retinal ganglion cells, particularly contributing to the papillomacular bundle, which leads to optic atrophy and loss of central vision (1). Typically, the clinical presentation includes acute or subacute central visual loss in one eye, with effects in the other eye 2-4 months later (2), although symptoms occur in the two eyes simultaneously in $25 \%$ of patients (3). The disease was first described by Leber in 1871 (4), Wallace et al reported the mitochondrial DNA (mtDNA) G11778A point mutation in patients with LHON in 1988 (5). In total $>95 \%$ of LHON pedigrees are known to exhibit one of three major mtDNA point causative mutations: G3460A (13\% of cases), G11778A (69\% of cases) and T14484C (14\% of cases) (6), which are located in the ND1, ND4 and ND6 mtDNA genes, respectively, and affect the genes encoding complex I subunits of the mitochondrial respiratory chain, which lead to disorders of the oxidative phosphorylation system $(7,8)$. However, the three major mutations are only responsible for $38.3 \%$ cases in Chinese individuals with LHON (9) and a number of other pathogenic mtDNA variants have been reported, which are awaiting confirmation for LHON pathogenicity (10).

At present, two key features of LHON require clarification. There is a marked incomplete penetrance and gender bias, with only $50 \%$ of male and $10 \%$ of female carriers eventually losing their vision (11). This indicates that there are additional genetic or environmental factors in the pathophysiology of the disorders. From then on, the importance of the mitochondrial haplogroup has been considered. A haplogroup is a collection of polymorphisms, which reflect the evolutionary history of the mtDNA molecule (12). In western European, the J2 and J1 haplogroups have been reported to contribute to increased risk of visual failure in families with G11778A and G3460A mutations, respectively (13). In Chilean patients, the Amerindian haplogroup A2 has been associated with delayed onset of LHON and haplogroup $\mathrm{C}$ has been associated with improved vision (14). In a previous study, which investigated Chinese patients of G11778A haplogroup F, a protective effect against LHON was observed, whilst haplogroups M7b and M10a were identified as risk factors $(15,16)$. The present study aimed to detect LHON-associated mutations and mitochondrial haplotypes in two families, and investigate the effects of the 
Table I. Clinical characteristics of patients carrying the G11778A mutation.

\begin{tabular}{lccccc}
\hline & & & \multicolumn{2}{c}{ Visual acuity } & \\
Patient & Age (years)/gender & Onset age (years) & Right eye & Left eye & Level of visual impairment \\
\hline Family 1-I-2 & 75/M & N/A & 0.04 & 0.06 & Severe \\
Family 1-III-5 & $17 / \mathrm{F}$ & 17 & 0.05 & 0.01 & Severe \\
Family 2-II-1 & $57 / \mathrm{F}$ & 17 & 0.01 & HM & Profound \\
Family 2-III-11 & $12 / \mathrm{F}$ & 12 & 0.05 & 0.02 & Severe
\end{tabular}

M, male; F, female; N/A, not available; HM, hand motions (ability to visually detect movement at short distances).

interaction between mutations and mitochondrial haplotypes on the phenotypic manifestation of LHON.

\section{Materials and methods}

Participants. Individuals from two unrelated families, each containing 22 members, were selected, and certain family members (marked with an asterisk in Fig. 1) were enrolled in the present study. Prior to involvement in the clinical evaluations, informed consent and blood samples were obtained from all the family members involved. Also, informed consent was obtained from family members for minors involved in this study. The present study was approved by the Ethics Committee of Zhongnan Hospital of Wuhan University (Wuhan, China) and was in line with the Declaration of Helsinki. Personal and family medical histories, history of tobacco use and alcohol intake, and details of any other clinical abnormalities were also obtained.

Ophthalmologic evaluations. The ophthalmologic examinations of all patients and available relatives were performed in the department of Ophthalmology at Zhongnan Hospital of Wuhan University (Wuhan, China). The examinations included measuring visual acuity, fundus examination, visual field examination, visual evoked potentials (VEP), fundus photography (TRC-50EX Fundus; Topcon Itabashi-ku Corporation, Tokyo, Japan), and head, orbital and cervical spine magnetic resonance imaging (MRI; Magnetom Trio Tim 3.0 MRI; Siemens, Munich, Germany). The level of visual impairment was defined according to the visual acuity, as follows: Normal, $\geq 0.3 ; 0.1 \leq$ mild $<0.3 ; 0.05 \leq$ moderate $<0.1 ; 0.02 \leq$ severe $<0.05$; and profound, $<0.02$.

Mutational analysis. Venipuncture was performed on all the family members participated, with the exception of family 1-I-2. Approximately $2 \mathrm{ml}$ EDTA-anticoagulant peripheral blood was drawn from participants for DNA collection. Approximately $0.5 \mathrm{ml}$ blood and 3X Red Blood Cell Lysis Buffer $(1 \mathrm{mM}$, $1.5 \mathrm{ml}$ ) were adding to a $10-\mathrm{ml} \mathrm{EP}$ tube. The mixture was placed in an ice bath for 30 min prior to centrifugation at $13,700 \mathrm{x} \mathrm{g}$ for $10 \mathrm{~min}$ at $4^{\circ} \mathrm{C}$ (TGL-18R; Hema Medical Instruments Co., Ltd., Zhuhai, China). The upper aqueous component was removed and $3 \mathrm{X}$ nucleus pyrolysis liquid ( $1 \mathrm{mM}, 1.5 \mathrm{ml}), 150 \mu \mathrm{l}$ of $10 \%$ sodium dodecyl sulphate (SDS) and $15 \mu \mathrm{l}$ of $10 \mathrm{mg} / \mathrm{ml}$ proteinase K (Sigma-Aldrich, St. Louis, MO, USA) were added, and the mixture was put into the Oven Controlled Crystal Oscillator (IS-RSV1; Crystal Technology and Industries, Inc., Dallas, TX, USA) at $37^{\circ} \mathrm{C}$ and $200 \mathrm{x}$ g overnight. Then the digestion solution was gently mixed with equal volume of Tris-phenol ( $2 \mathrm{mM}, \mathrm{pH} 8.0$ ). The phases were separated by centrifugation at $13,700 \mathrm{x} \mathrm{g}$ for $10 \mathrm{~min}$ at $4^{\circ} \mathrm{C}$. The upper aqueous component was retained and equal volume of Phenol/chloroform (volume, 1:1) was added, then the mixture was centrifuged at $13,700 \mathrm{xg}$ for $10 \mathrm{~min}$ at $4^{\circ} \mathrm{C}$. The majority of the aqueous phase was transferred into a $1.5 \mathrm{ml}$ EP tube prior to mixing with $1 \mathrm{ml}$ of $70 \%$ ethanol. Later the phases were separated by centrifugation at room temperature at $13,700 \times \mathrm{g}$ for $10 \mathrm{~min}$ twice. The aqueous phase was decanted and the precipitation contained the desired DNA. After draining excess liquid, the precipitation was dissolved with $50 \mu \mathrm{TE}$ and stored at $4^{\circ} \mathrm{C}$. While the genomic DNA of family 1-I-2 was extracted using a Chelex-100 (Bio-Rad Laboratories, Inc., Hercules, CA, USA) method from the scapus pili. The mtDNA fragments of ND1, ND4 and ND6, which contain three major mutations (G3460A, G11778A and T14484C), were amplified from the DNA extracted from all family members involved. The PCR products were directly sequenced using one of the PCR primers. The sequences were blasted with the reference sequences to identify the mutations. The amplification of the entire mtDNA of the two probands were performed using previously defined 24 primers, covering overlapped fragments, using polymerase chain reaction (PCR) (17). Each amplification reaction contained $5.0 \mu \mathrm{l}$ of 10X Ex Taq Buffer, $5.0 \mu \mathrm{lgCl}_{2}(25 \mathrm{mM}), 2.0 \mu \mathrm{l}$ of $4 \mathrm{X} \mathrm{dNTP}$ ( $2 \mathrm{mM}), 2.0 \mu \mathrm{l}$ of $1 \mathrm{mM}$ each primer, 2 units of Taq polymerase (Thermo Fisher Scientific, Inc., Waltham, MA, USA), $3.0 \mu 1$ genomic DNA and double distilled water was added to reach $50 \mathrm{ml}$ reaction volume. The protocol for amplification reactions was as follows: Denaturation at $95^{\circ} \mathrm{C}$ for $5 \mathrm{~min}$ followed by 35 cycles of a denaturation at $94^{\circ} \mathrm{C}$ for $30 \mathrm{sec}$, an annealing at $52-63^{\circ} \mathrm{C}$ for $30 \mathrm{sec}$ and an extension at $72^{\circ} \mathrm{C}$ for $45 \mathrm{sec}$, the terminal extension step at $72^{\circ} \mathrm{C}$ for $10 \mathrm{~min}$. The amplification was conducted using a Hema 9600 PCR thermocycler (Hema Medical Instruments Co., Ltd.) and a 3130xl Genetic Analyzer (Applied Biosystems Life Technologies, Carlsbad, CA, USA). The bidirectional sequence results were analyzed and compared with the updated consensus revised Cambridge reference sequence (GenBank accession no. NC_012920). Changes in the mtDNA were compared against a mitochondrial database, including Mitomap (www.mitomap.org/MITOMAP) and mtDB (www.mtdb.igp.uu.se/). 

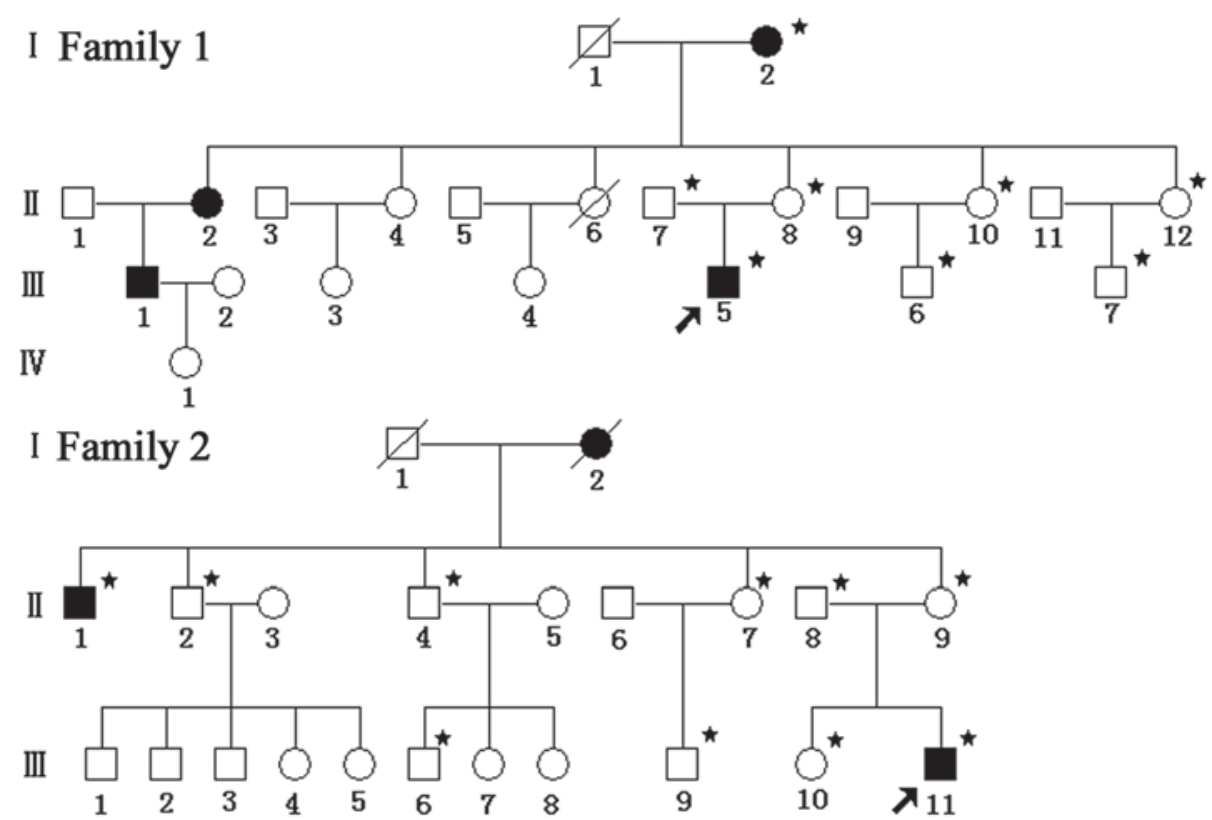

Figure 1. Families with LHON. Squares indicate males and circles indicate females. The black and white symbols indicate the patients with LHON and unaffected individuals, respectively. The slash through the symbol represents deceased. The black arrows indicate the proband and the asterisk denotes the members involved in the present study. LHON, Leber's hereditary optic neuropathy.

Phylogenetic analysis. Conservative amino acid analyses of missense mutations were identified in the Mitochondrial Single Nucleotide Polymorphism public database (http://mtsnp.tmig. or.jp/mtsnp/index_e.shtml), which compared the human amino acid variants with those of 60 vertebrates, including Artibeus jamaicensis, Didelphis virginiana and Hippopotamus amphibius. The degree of conservation is defined as the percentage of species in the 60 vertebrates with the same amino acid in the same position as in humans (18).

Haplogroup analyses. The entire mtDNA sequence of the probands was assigned to mitochondrial haplogroups using the nomenclature of the mitochondrial haplogroups (19), according to PhyloTree (http://www.phylotree.org/) (20).

\section{Results}

In family 1, the proband (III-5) was a 17 year old male from Henan, China. This individual developed impaired vision in the right eye, followed four days later by impaired vision in the left eye, with no clear cause. As presented in Table I, III-5 presented with 0.05 visual acuity in the right eye and 0.01 visual acuity in the left eye, with dense central scotomas and optic disk pallor bilaterally (21). Visual field analysis revealed large visual field defects connected to the physiological blind spot in the right and left eye. The flash VEP demonstrated bilateral delays in the amplitudes of the latency. No other clinical abnormalities were observed on the head, orbital and cervical spine MRI. In addition, III-5 had a history of tobacco and alcohol use for almost two years. In the matrilineal relatives, there were 2 affected males and 2 affected females; thus, the ratio of affected males to females was 1:1. However, in total there were 4 males and 9 females in this family. Thus, the morbidity of males and females was $2 / 4$ and $2 / 9$, respectively. The ratio of $2 / 4$ to $2 / 9$ was the incidence between the males and females, which equaled

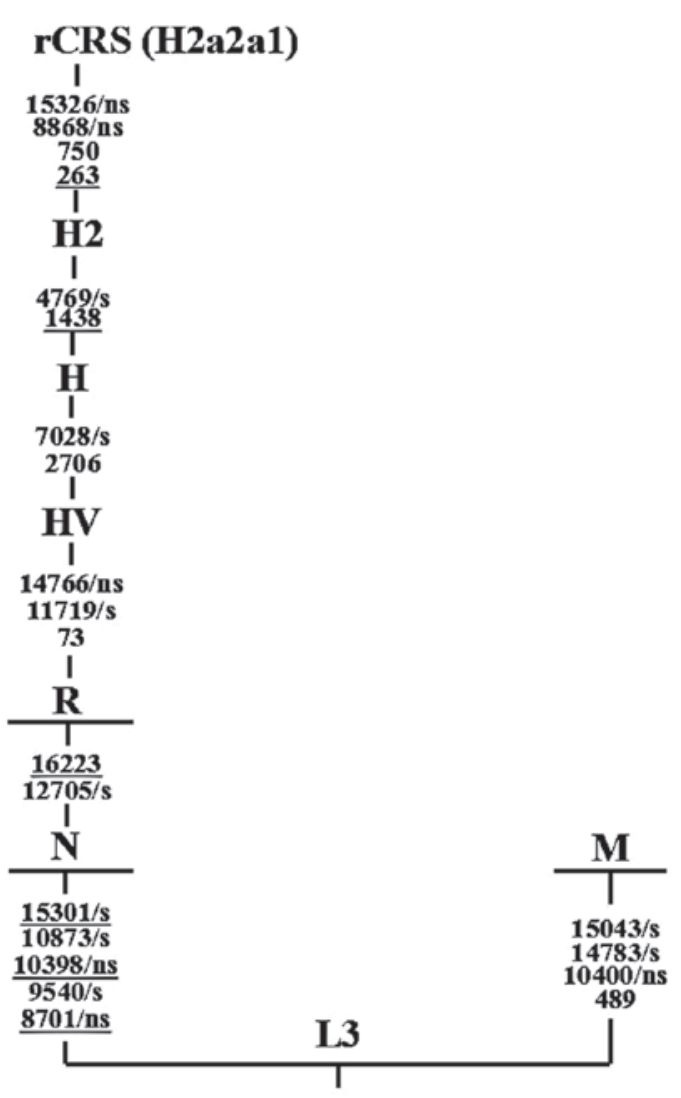

Figure 2. rCRS $(12,13)$. The rCRS represents the nodal H2a2a1. haplogroup Recurrent mutations are underlined. The synonymous and non-synonymous coding-region variants in the mitochondrial DNA sequences are denoted by '/s' and '/ns', respectively. rCRS, revised Cambridge reference sequence.

2.25:1, and the penetrance of visual loss (affected matrilineal relatives/total matrilineal relatives) was $30.8 \%$. 
Table II. List of the mtDNA variants identified in the two families containing individuals diagnosed with Leber's hereditary optic neuropathy.

\begin{tabular}{|c|c|c|c|c|c|c|}
\hline Gene & Position & Replacement & CRS & Family 1 & Family 2 & $\begin{array}{c}\text { Conservative } \\
\text { degree }^{\mathrm{a}}(\%)\end{array}$ \\
\hline \multirow[t]{14}{*}{ D-loop } & 73 & $A>G$ & $\mathbf{A}$ & G & G & \\
\hline & 146 & $\mathrm{~T}>\mathrm{C}$ & $\mathrm{T}$ & $\mathrm{C}$ & $\mathrm{C}$ & \\
\hline & 152 & $\mathrm{~T}>\mathrm{C}$ & $\mathrm{T}$ & $\mathrm{C}$ & $\mathrm{C}$ & \\
\hline & 204 & $\mathrm{~T}>\mathrm{C}$ & $\mathrm{T}$ & - & C & \\
\hline & 263 & $\mathbf{A}>\mathbf{G}$ & $\mathbf{A}$ & G & G & \\
\hline & 272 & $A>G$ & A & - & G & \\
\hline & 489 & $A>G$ & $\mathrm{~T}$ & - & $\mathrm{C}$ & \\
\hline & 16093 & $\mathrm{~T}>\mathrm{C}$ & $\mathrm{T}$ & $\mathrm{C}$ & $\mathrm{C}$ & \\
\hline & 16193 & $\mathrm{C}>\mathrm{T}$ & $\mathrm{C}$ & $\mathrm{T}$ & $\mathrm{T}$ & \\
\hline & 16223 & $C>T$ & $\mathbf{C}$ & $\mathbf{T}$ & $\mathbf{T}$ & \\
\hline & 16311 & $\mathrm{~T}>\mathrm{C}$ & $\mathrm{T}$ & - & $\mathrm{C}$ & \\
\hline & 16357 & $\mathrm{~T}>\mathrm{C}$ & $\mathrm{T}$ & $\mathrm{C}$ & $\mathrm{C}$ & \\
\hline & 16497 & $A>G$ & A & G & G & \\
\hline & 16519 & $\mathrm{~T}>\mathrm{C}$ & $\mathrm{T}$ & $\mathrm{C}$ & - & \\
\hline \multirow{3}{*}{ 12SrRNA } & 709 & $\mathrm{G}>\mathrm{A}$ & G & A & A & \\
\hline & 750 & $\mathbf{A}>\mathbf{G}$ & $\mathbf{A}$ & $\mathbf{G}$ & $\mathbf{G}$ & \\
\hline & 1438 & $A>G$ & $\mathbf{A}$ & G & G & \\
\hline 16SrRNA & 2706 & $A>G$ & $\mathrm{~A}$ & G & G & \\
\hline \multirow[t]{2}{*}{ NDI } & 3394 & $\mathrm{~T}>\mathrm{C}$ (Ty83His) & $\mathrm{T}$ & $\mathrm{C}$ & - & 96.7 \\
\hline & 4140 & $\mathrm{C}>\mathrm{T}$ & $\mathrm{C}$ & $\mathrm{T}$ & $\mathrm{T}$ & \\
\hline ND2 & 4769 & $\mathbf{A}>\mathbf{G}$ & $\mathbf{A}$ & $\mathbf{G}$ & G & \\
\hline \multirow[t]{3}{*}{$\mathrm{COI}$} & 6965 & $\mathrm{~T}>\mathrm{G}$ & $\mathrm{T}$ & G & - & \\
\hline & 7028 & $C>T$ & $\mathbf{C}$ & $\mathbf{T}$ & $\mathbf{T}$ & \\
\hline & 7250 & $A>G$ & A & G & G & \\
\hline \multirow[t]{5}{*}{ ATP6 } & 8701 & A>G (Thr59Ala) & $\mathbf{A}$ & G & G & 28.3 \\
\hline & 8764 & $\mathrm{~A}>\mathrm{G}($ Ala80Thr $)$ & $\mathrm{G}$ & - & A & 26.7 \\
\hline & 8793 & $\mathrm{~T}>\mathrm{C}$ & $\mathrm{T}$ & $\mathrm{C}$ & $\mathrm{C}$ & \\
\hline & 8856 & $\mathrm{G}>\mathrm{A}$ & $\mathrm{G}$ & A & A & \\
\hline & 8860 & A>G (Thr112Ala) & $\mathbf{A}$ & $\mathbf{G}$ & $\mathbf{G}$ & 66.7 \\
\hline COIII & 9540 & $\mathbf{T}>\mathbf{C}$ & $\mathbf{T}$ & $\mathbf{C}$ & $\mathbf{C}$ & \\
\hline \multirow[t]{2}{*}{ ND3 } & 10398 & $A>G($ Thr114Ala $)$ & $\mathbf{A}$ & $\mathbf{G}$ & $\mathbf{G}$ & 43.3 \\
\hline & 10400 & $\mathrm{C}>\mathrm{T}$ & $\mathrm{C}$ & $\mathrm{T}$ & $\mathrm{T}$ & \\
\hline \multirow[t]{2}{*}{ ND4L } & 10529 & $A>G$ & A & - & G & \\
\hline & 10646 & $\mathrm{G}>\mathrm{A}$ & $\mathrm{G}$ & A & A & \\
\hline \multirow[t]{6}{*}{ ND4 } & 10873 & $\mathbf{T}>\mathbf{C}$ & $\mathbf{T}$ & C & $\mathbf{C}$ & \\
\hline & 10203 & $\mathrm{C}>\mathrm{T}$ & $\mathrm{C}$ & - & $\mathrm{T}$ & \\
\hline & 11674 & $\mathrm{C}>\mathrm{T}$ & $\mathrm{C}$ & - & $\mathrm{T}$ & \\
\hline & 11719 & $\mathbf{G}>\mathbf{A}$ & G & A & A & \\
\hline & 11778 & $\mathrm{G}>\mathrm{A}$ (Arg340His) & $\mathrm{G}$ & $\mathrm{A}$ & $\mathrm{A}$ & 98.3 \\
\hline & 12034 & $\mathrm{C}>\mathrm{T}$ & $\mathrm{C}$ & $\mathrm{T}$ & - & \\
\hline \multirow[t]{7}{*}{ ND5 } & 12549 & $\mathrm{C}>\mathrm{T}$ & $\mathrm{C}$ & $\mathrm{T}$ & $\mathrm{T}$ & \\
\hline & 12705 & $C>T$ & $\mathbf{C}$ & $\mathbf{T}$ & $\mathbf{T}$ & \\
\hline & 13135 & $\mathrm{G}>\mathrm{A}(\mathrm{Ala} 267 \mathrm{Thr})$ & $\mathrm{G}$ & A & - & 5.0 \\
\hline & 13152 & $\mathrm{~A}>\mathrm{G}$ & A & G & G & \\
\hline & 13774 & $\mathrm{~A}>\mathrm{G}(\mathrm{Thr} 480 \mathrm{Ala})$ & $\mathrm{A}$ & - & G & - \\
\hline & 14097 & $\mathrm{C}>\mathrm{T}$ & $\mathrm{C}$ & $\mathrm{T}$ & - & \\
\hline & 14110 & $\mathrm{~T}>\mathrm{C}$ & $\mathrm{T}$ & - & $\mathrm{C}$ & \\
\hline ND6 & 14502 & $\mathrm{~T}>\mathrm{C}$ (Ile58 Val) & $\mathrm{T}$ & $\mathrm{C}$ & $\mathrm{C}$ & 26.7 \\
\hline
\end{tabular}


Table II. Continued.

\begin{tabular}{|c|c|c|c|c|c|c|}
\hline Gene & Position & Replacement & CRS & Family 1 & Family 2 & $\begin{array}{c}\text { Conservative } \\
\text { degree }^{\mathrm{a}}(\%)\end{array}$ \\
\hline \multirow[t]{6}{*}{ CytB } & 14766 & C > T (Thr7Ile) & C & $\mathbf{T}$ & $\mathbf{T}$ & 50.0 \\
\hline & 14783 & $\mathrm{~T}>\mathrm{C}$ & $\mathrm{T}$ & C & $\mathrm{C}$ & \\
\hline & 15043 & $\mathrm{G}>\mathrm{A}$ & G & A & - & \\
\hline & 15301 & $\mathbf{G}>\mathbf{A}$ & $\mathbf{G}$ & $\mathbf{A}$ & $\mathbf{A}$ & \\
\hline & 15326 & $A>G$ & $\mathbf{A}$ & $\mathbf{G}$ & G & \\
\hline & 15526 & $\mathrm{C}>\mathrm{T}$ & $\mathrm{C}$ & - & $\mathrm{T}$ & \\
\hline
\end{tabular}

Conservative degree ${ }^{a}$ was determined by comparing the Homo sapiens mtDNA variants with 60 other vertebrates. The variations used to determine the haplogoup affliation of mtDNA are highlighted in bold. mtDNA, mitochondrial DNA; CRS, Cambridge reference sequence.

In family 2 , the proband (III-11) was a 12 year old male from Hubei, China, who exhibited painless, progressive deterioration of the left eye, followed by rapid vision loss in his right eye 11 months later. Visual acuity was 0.05 and 0.02 in the right and left eyes, respectively. No other clinical abnormalities of the eye were observed. The ratio between the number of affected males and females was 2:1 and the incidence in males and females was $2 / 5$ and 1/4 respectively. Therefore, the males:female incidence ratio was 1.6:1 and the penetrance of visual loss was $33.3 \%$.

In order to elucidate the molecular basis of LHON, mutational screening of three major mutations, G3460A, G11778A and T14484C, was performed in the two families using PCR direct bidirectional sequencing. The results revealed the presence of G11778A in the two families, but absence of the G3460A and T14484C mutations.

To determine the role of the haplogroup in the phenotypic expression of the G11778A mutation, the entire mitochondrial genome was analyzed using PCR direct sequencing, as shown in Table II. These missense variants were further evaluated by phylogenetic analysis among 60 types of vertebrate, particularly the T3394C and T14502C mutations, which are considered to be secondary mutations in the expression of $\operatorname{LHON}(18,21,22)$. The analyses revealed that T3394C was highly conserved in $58 / 60$ mammalian species and the conservative degree was $96.7 \%$. G11778A was highly conserved in 59/60 mammalian species, with a conservative degree of $98.3 \%$. The degree of conservation of $\mathrm{T} 14502 \mathrm{C}$ was $72.13 \%$, which suggested it as a potential polymorphism. The analyses of the complete mtDNA sequences indicated that the two families exhibited the $\mathrm{H} 2 \mathrm{a} 2 \mathrm{a} 1$ haplogroup (Fig. 2).

\section{Discussion}

In the present study, according to the typical clinical signs, symptoms and family histories, the probands were diagnosed as having LHON $(22,23)$. Genetic and molecular characterization of the matrilineal relatives was subsequently conducted. The G11778A mutations were observed in all maternal members in the two families and were in the $\mathrm{H} 2 \mathrm{a} 2 \mathrm{a} 1$ haplogroup.

In previous reports, the average penetrance of visual loss was $19.2 \%$ in 11 families, who were carrying only the G11778A mutation, while the average penetrance of visual loss in four families carrying the G11778A and T14502C mutations was
$38.8 \%(24,25-27)$. In addition, the penetrances of visual loss in families carrying T3394C and G11778A mutations have been reported as 38, 38, 44 and $56 \%$ (28). In the present study, the penetrances of visual loss in family 1 and family 2 were 30.8 and $33.3 \%$, respectively. This suggested that the G11778A mutation itself was not sufficient to induce visual loss, while the second mutations were. Subsequently, conservative analysis of the missense mutations, which were identified in the genotype analysis of the two families, was performed. The T3394C mutation was highly conserved, while T14502C and the other missense variants were potential polymorphisms. Therefore, the T3394C mutation may cooperate with the G11778A variant to contribute to the penetrance of LHON. Although the T14502C variant was identified as a potential polymorphism, it has been previously reported to act synergistically with the T11778C mutation (24).

The penetrances of visual loss were 30.8 and $33.3 \%$ in the two families, which were lower than those carrying either the T14502C or T3394C second mutation. It was suggested that the $\mathrm{H} 2 \mathrm{a} 2 \mathrm{a} 1$ haplogroup had a protective effect on the phenotypic manifestation of LHON, similar to a previous observation, in which haplogroup $\mathrm{H}$ had a protective effect in families carrying the G11778A mutation (13). However, it is not possible to exclude the small sample size as a cause for the deviation.

When comparing the probands of families 1 and 2, age-at-onset was $<20$ years old, severe visual impairment was present, and the G11778A mutation and $\mathrm{H} 2 \mathrm{a} 2 \mathrm{a} 1$ haplogroup were identified in both families. In family 1 , the proband carrying T3394C and T14502C mutations, presented initially with loss of vision in one eye. Loss occurred in the other eye shortly after, indicating the rapid development of the disease in this patient. However, in family 2 the proband only carried the T14502C mutation, and vision loss began in his second eye 11 months following loss of vision loss in his first eye. This indicates a slower development of the disease compared with that in family 1. Therefore, we hypothesized that carrying a second mutation increased the rate of visual impairment. It was suggested that individuals with the two second mutations in family 1 were more likely to have shorter intervals between the loss of vision in the right and left eyes. It is generally accepted that possessing more second mutations may increase the penetrance of LHON (29), however, this was not observed in the present study. Additional modifying factors including environmental factors, lifestyle, estrogen levels and nuclear genes may be important in 
LHON (30,31). Cytoplasmic hybrid (cybrid) cell model experiments have previously demonstrated that estrogen may reduce the production of reactive oxygen species in complex I-defective LHON cybrids, improve cybrid energetic competence and lead to coordinated activation of mitochondrial biogenesis (32). Additionally, estrogen receptor $\beta$ has been observed to localize to the human retinal ganglion cells and the retinal nerve fibre layer (32). A previous study observed that a female with Perrault syndrome, which leads to a reduction in estrogen, also suffered a severe manifestation of LHON due to the G11778A mtDNA mutation (33), which further suggested that estrogen has an important function in LHON. The variation in the PARL gene of LHON also suggested that it may be involved in the penetrance of the disease (34).

In conclusion, in the small sample of patients examined in the present study, patients with LHON who carry the G11778A mutation were observed to carry two second mutations, T14502C and T3394C, and were more likely to exhibit shorter intervals between visual loss in the right and left eyes. In addition, the H2a2a1 haplogroup may have a protective effect on the phenotypic manifestation of LHON.

\section{Acknowledgements}

The authors would like to thank the patients and family members who were involved in and Dr Changzheng Chen at Renmin Hospital of Wuhan University (Wuhan, China) for his cooperation.

\section{References}

1. Carelli V, Ross-Cisneros FN and Sadun AA: Mitochondrial dysfunction as a cause of optic neuropathies. Prog Retin Eye Res 23: 53-89, 2004.

2. Fraser JA, Biousse V and Newman NJ: The neuro-ophthalmology of mitochondrial disease. Surv Ophthalmol 55: 299-334, 2010.

3. Sitarz KS, Chinnery PF and Yu-Wai-Man P: Disorders of the optic nerve in mitochondrial cytopathies: new ideas on pathogenesis and therapeutic targets. Curr Neurol Neurosci Rep 12: 308-317, 2012.

4. Leber T: Ueber hereditaere und congenital angelegte sehnervenleiden. Graefes Arch Clin Exp Ophthalmol 17: 249-91, 187.

5. Wallace DC, Singh G, Lott MT, et al: Mitochondrial DNA mutation associated with Leber's hereditary optic neuropathy. Science 242: 1427-1430, 1988.

6. Mackey DA, Oostra RJ, Rosenberg T, et al: Primary pathogenic mtDNA mutations in multigeneration pedigrees with Leber hereditary optic neuropathy. Am J Hum Genet 59: 481-485, 1996.

7. Brandon MC, Lott MT, Nguyen KC, et al: MITOMAP: a human mitochondrial genome database - 2004 update. Nucleic Acids Res 33: D611-D613, 2005.

8. Carelli V, La Morgia C, Valentino ML, Barboni P, Ross-Cisneros FN and Sadun AA: Retinal ganglion cell neurodegeneration in mitochondrial inherited disorders. Biochim Biophys Acta 1787: 518-528, 2009.

9. Jia X, Li S, Xiao X, Guo X and Zhang Q: Molecular epidemiology of mtDNA mutations in 903 Chinese families suspected with Leber hereditary optic neuropathy. J Hum Genet 51: 851-856, 2006.

10. Yu-Wai-Man P, Griffiths PG and Chinnery PF: Mitochondrial optic neuropathies-disease mechanisms and therapeutic strategies. Prog Retin Eye Res 30: 81-114, 2011.

11. Brown MD and Wallace DC: Spectrum of mitochondrial DNA mutations in Leber's hereditary optic neuropathy. Clin Neurosci 2: 134-145, 1994.

12. Tońska K, Kodroń A and Bartnik E: Genotype-phenotype correlations in Leber hereditary optic neuropathy. Biochim Biophys Acta 1797: 1119-1123, 2010.

13. Hudson G, Carelli V, Spruijt L, et al: Clinical expression of Leber hereditary optic neuropathy is affected by the mitochondrial DNA-haplogroup background. Am J Hum Genet 81: 228-233, 2007.
14. Romero P, Fernández V, Slabaugh M, et al: Pan-American mDNA haplogroups in Chilean patients with Leber's hereditary optic neuropathy. Mol Vis 20: 334-340, 2014.

15. Zhang AM, Jia X, Bi R, et al: Mitochondrial DNA haplogroup background affects LHON, but not suspected LHON, in Chinese patients. PloS One 6: e27750, 2011.

16. Meng X, Zhu J, Gao M, et al: The analysis of mitochondrial DNA haplogroups and variants for Leber's hereditary optic neuropathy in Chinese families carrying the $\mathrm{m} .14484 \mathrm{~T}>\mathrm{C}$ mutation. $\mathrm{Y} i$ Chuan 36: 336-345, 2014 (In Chinese).

17. Rieder MJ, Taylor SL, Tobe VO and Nickerson DA: Automating the identification of DNA variations using quality-based fluorescence re-sequencing: analysis of the human mitochondrial genome. Nucleic Acids Res 26: 967-973, 1998.

18. Zhang S, Wang L, Hao Y, et al: T14484C and T14502C in the mitochondrial ND6 gene are associated with Leber's hereditary optic neuropathy in a Chinese family. Mitochondrion 8: 205-210, 2008.

19. Kong QP, Yao YG, Sun C, Bandelt HJ, Zhu CL and Zhang YP: Phylogeny of east Asian mitochondrial DNA lineages inferred from complete sequences. Am J Hum Genet 73: 671-676, 2003.

20. van Oven M and Kayser M: Updated comprehensive phylogenetic tree of global human mitochondrial DNA variation. Hum Mutat 30: E386-E394, 2009.

21. Lange C, Feltgen N, Junker B, Schulze-Bonsel K and Bach M: Resolving the clinical acuity categories 'hand motion' and 'counting fingers' using the Freiburg Visual Acuity Test (FrACT). Graefes Arch Clin Exp Ophthalmol 247: 137-142, 2009.

22. Carelli V, Ross-Cisneros FN and Sadun AA: Mitochondrial dysfunction as a cause of optic neuropathies. Prog Retin Eye Res 23: 53-89, 2004.

23. Fraser JA, Biousse V and Newman NJ: The neuro-ophthalmology of mitochondrial disease. Surv Ophthalmol 55: 299-334, 2010

24. Zhang J, Zhou X, Zhou J, et al: Mitochondrial ND6 T14502C variant may modulate the phenotypic expression of LHON-associated G11778A mutation in four Chinese families. Biochem Biophys Res Commun 399: 647-653, 2010.

25. Qu J, Li R, Tong Y, et al: Only male matrilineal relatives with Leber's hereditary optic neuropathy in a large Chinese family carrying the mitochondrial DNA G11778A mutation. Biochem Biophys Res Commun 328: 1139-1145, 2005.

26. Qian Y, Zhou X, Hu Y, et al: Clinical evaluation and mitochondrial DNA sequence analysis in three Chinese families with Leber's hereditary optic neuropathy. Biochem Biophys Res Commun 332: 614-621, 2005.

27. Qu J, Zhou X, Zhang J, et al: Extremely low penetrance of Leber's hereditary optic neuropathy in 8 Han Chinese families carrying the ND4 G11778A mutation. Ophthalmology 116: 558-564, e3, 2009.

28. Zhang M, Zhou X, Li C, et al: Mitochondrial haplogroup M9a specific variant ND1 T3394C may have a modifying role in the phenotypic expression of the LHON-associated ND4 G11778A mutation. Mol Genet Metab 101: 192-199, 2010.

29. Torroni A, Petrozzi M, D'Urbano L, et al: Haplotype and phylogenetic analyses suggest that one European-specific mtDNA background plays a role in the expression of Leber hereditary optic neuropathy by increasing the penetrance of the primary mutations 11778 and 14484. Am J Hum Genet 60: 1107-1121, 1997.

30. Giordano C, Montopoli M, Perli E, et al: Oestrogens ameliorate mitochondrial dysfunction in Leber's hereditary optic neuropathy. Brain 134: 220-234, 2011.

31. Yu-Wai-Man P, Griffiths PG, Hudson G and Chinnery PF: Inherited mitochondrial optic neuropathies. J Med Genet 46: 145-158, 2009.

32. Giordano C, Montopoli M, Perli E, et al: Oestrogens ameliorate mitochondrial dysfunction in Leber's hereditary optic neuropathy. Brain 134: 220-234, 2011.

33. Badura-Stronka M, Wawrocka A, Zawieja K, Silska S and Krawczyński MR: Severe manifestation of Leber's hereditary optic neuropathy due to $11778 \mathrm{G} \mathrm{A}$ mtDNA mutation in a female with hypoestrogenism due to Perrault syndrome. Mitochondrion 13: 831-834, 2013.

34. Istikharah R, Tun AW, Kaewsutthi $\mathrm{S}$, et al: Identification of the variants in PARL, the nuclear modifier gene, responsible for the expression of LHON patients in Thailand. Exp Eye Res 116: $55-57,2013$ 